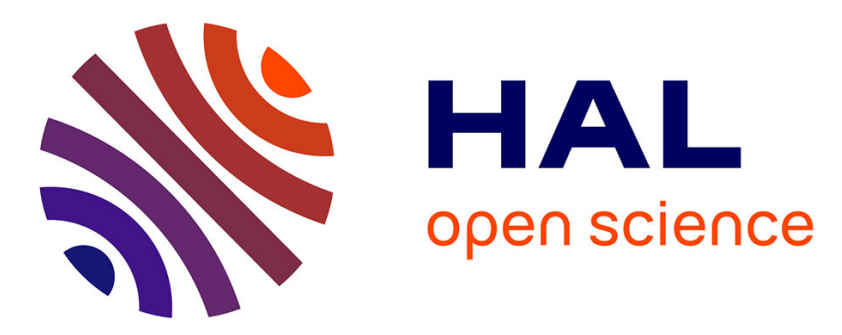

\title{
Plastic strain localization induced by microstructural gradient in laser cladding repaired structures
}

Camille Guévenoux, Simon Hallais, Yanis Balit, Alexandre Charles, Eric Charkaluk, Andrei Constantinescu

\section{- To cite this version:}

Camille Guévenoux, Simon Hallais, Yanis Balit, Alexandre Charles, Eric Charkaluk, et al.. Plastic strain localization induced by microstructural gradient in laser cladding repaired structures. Theoretical and Applied Fracture Mechanics, 2020, 107, pp.102520. 10.1016/j.tafmec.2020.102520 . hal02509924

\section{HAL Id: hal-02509924 \\ https://hal.science/hal-02509924}

Submitted on 17 Mar 2020

HAL is a multi-disciplinary open access archive for the deposit and dissemination of scientific research documents, whether they are published or not. The documents may come from teaching and research institutions in France or abroad, or from public or private research centers.
L'archive ouverte pluridisciplinaire HAL, est destinée au dépôt et à la diffusion de documents scientifiques de niveau recherche, publiés ou non, émanant des établissements d'enseignement et de recherche français ou étrangers, des laboratoires publics ou privés. 


\title{
Plastic strain localization induced by microstructural gradient in laser cladding repaired structures
}

\author{
Camille Guévenoux ${ }^{\mathrm{a}, \mathrm{b}}$, Simon Hallais ${ }^{\mathrm{a}}$, Yanis Balit ${ }^{\mathrm{a}}$, Alexandre Charles ${ }^{\mathrm{b}}$, Eric Charkaluk ${ }^{\mathrm{a}}$, Andrei \\ Constantinescu ${ }^{\mathrm{a}}$ \\ ${ }^{a}$ Laboratoire de Mécanique des Solides, École polytechnique, Institut Polytechnique de Paris, CNRS, Palaiseau, France \\ ${ }^{b}$ Safran Tech, Magny-les-Hameaux, France
}

\begin{abstract}
Laser Cladding is an additive manufacturing technology well suited for the repair of complex metallic components. The repair is a two-step process: first, one removes the worn region and then, the initial geometry is reconstructed locally. The aim of this work is to study the influence of the microstructural gradient on the strain localization in repaired structures. More precisely, we perform in-situ SEM tensile tests completed by EBSD observations of the microstructure in the interface neighborhood between the base material and the repaired region. Furthermore, we monitor the evolution of the local plastic strain distribution at the grain level until failure. This is performed by Digital Image Correlation methods and superposition of grains contours and strain maps. The observations of grain size and plasticity are compared with predictions provided by a Hall-Petch model. The study emphasizes the importance of the microstructural gradient in the vicinity of reparation interface, more precisely it reveals that this gradient induce multiaxial strains and that the strain localization phenomenon is governed mainly by a grain size effect.
\end{abstract}

Keywords: Additive manufacturing, Laser Cladding repair, SEM in-situ tests, strain localization, microstructural gradient.

\section{Introduction}

The repair of valuable metallic components has become a major asset for industries. This is a consequence of high cost of both technological alloys and manufacturing of complex structures [1]. Laser Cladding, also denoted as Directed Energy Deposition or Laser Metal Deposition, is an additive manufacturing process that permits to add locally material on an existing part or structure, enabling for example the repair of a worn out region. The material deposition system consists of a nozzle, where the metallic powder jet will encounter a coaxial laser beam and will be projected on the part. Laser Cladding is a highly promising technology, as its subsequent Heat Affected Zone (HAZ) has a small size, when compared with other repair processes such as Tungsten Inert Gas or Gas Metal Arc Welding [2-4].

The microstructure obtained by Laser Cladding process is specific and differs from the ones generated by conventional processes, like forge or foundry. Indeed, the heat input is highly localized due to the small size of the laser spot and this leads to a pronounced spatial thermal gradient. Moreover, the rapid motion of the nozzle and the ratio between the volume of the deposited material and that of the part lead to extremely high cooling rates. This peculiar thermal field with high spatial and temporal gradients will govern the growth of the additive manufactured material and its final microstructure. Besides, the material experiences a first solidification as the melt pool follows the motion of the laser, but can experience additional remelting, when the layers above are built. The global thermal evolution in the material is close to an annealing process as the part remains at high temperatures until the end of the process $[5,6]$ and can steer further metallurgical transformations.

Email address: camille.guevenoux@polytechnique.edu (Camille Guévenoux) 
The final microstructure of each material volume element is therefore a function of its thermal history, which depends directly on the process parameters: laser power, velocity of the nozzle, powder flow rate... This influence has been recognized and investigated in the last decades. Among the rich literature of this subject, one can mention the following ones focusing on the impact of laser speed, laser power and powder flow rate [7-9], linear energy input (laser power divided by laser speed) [10, 11], lasing strategy [4, 8, 12-14] and inter-layer dwell time [15-17]. The inclusion of dwell time between the writing of two successive layers introduces an additional cooling period in the process and therefore changes the thermal field both in terms of history and in terms of temporal or spatial gradients $[5,16]$. This will affect the final geometrical distorsion of the part and the underlying residual stresses $[15,16]$ as well as the microstructure and consequently the mechanical and fatigue behavior, characterized for example by microhardness [17, 18].

Repaired components contain an interface, which separates the initial structure from the added zone. The added zone is also designated as the cladded zone in the field. A fine inspection of the vicinity of the interface will reveal a microstructural gradient and Heat Affected Zone, which are once again driven by the thermal history. This interface needs to be examined in detail to ensure the metallurgical cohesion between the added material and the original part and thereafter to assess the lifetime of the repaired component. In the literature, several repaired configurations can be found, where the microstructural gradient around the interface, the global mechanical behavior (yield stress, ultimate tensile stress, ductility) or the failure location are investigated [3, 19-26]. Besides, microstructural gradients can also induce a local multiaxial response in a component submitted to a global uniaxial loading [27]. Taking into account the local multiaxiality is consequently essential to know the fracture modes that will occur.

Strain maps from in-situ observations acquired during mechanical tests can be assembled using recent developments of Digital Image Correlation (DIC) techniques [28]. In [29], Zhao et al. conducted tensile tests with DIC at a macroscopic level on specimens including a small repaired region in the gauge section. They have shown that for titanium alloys the existence of a microstructural gradient caused by the repair induces strain localization. In [30], Sui et al. also performed tensile tests monitored by macroscopic DIC on repaired samples. They cut thin specimens in a massive Inconel 718 plate which is half wrought and half manufactured by laser cladding. At the macroscopic scale, their study highlights that the repaired region deforms more than the substrate and the authors state that this is due to the presence of Laves phases in the cladded part. Other studies use DIC at a smaller scale to highlight spatial distribution of strain within grains [31-34]. A combination of these techniques were used in [35] to investigate strain localization pattern in additively manufactured 316 stainless steel and explain the observed macroscopic anisotropy of the material.

The aim of the present work is to provide a study on repaired Inconel 718 components complementary to what was done by Sui et al. in [30] in order to understand the consequence of microstructural gradient on plastic strain localization. Indeed, in their work, Sui et al. manufactured massive components with change of lasing direction from one layer to the other. This generates a complicated three-dimensional microstructure which can be hard to analyze. Consequently, the specimens of the present work are taken on single-track walls with simpler microstructures. Moreover, observing the strain distribution at a lower scale would give additional information on localization phenomenon. In the present study, strain maps are acquired at the grain level with a DIC pitch of $3 \mu \mathrm{m}$. This scale was chosen to provide an intermediary information between macroscopic features (interface between wrought substrate and cladded region) and localization on metallurgical phases. Moreover, several microstructures and gradient were generated by introducing an interlayer dwell time in the process and the resulting strain localization patterns are compared.

The paper starts with the presentation of the material under scrutiny and the investigation methods. Next, the results of the observations are exposed and commented: microstructure in the neighborhood of the interface, spatial evolution of parameters, as well as the distribution of plastic strain. Furthermore, the observations of plastic grain size and plasticity are compared with predictions provided by a Hall-Petch model. Additional observations emphasized the local defects along the failure surface. The limits and extensions of the present work are discussed in the final section. 


\section{Material and methods}

\subsection{Manufacturing the repaired specimen}

The experimental work was conducted on repaired specimens of the geometry displayed in Fig. 1. The repaired structure consists of an initial vertical thin plate playing the part of the substrate on top of which a single-track wall is deposited by Laser Cladding.

The material used in this study is a nickel alloy, Inconel 718 [36]. The substrate is wrought Inconel 718 plate with dimensions: $1.6 \mathrm{~mm}$ thick, $90 \mathrm{~mm}$ long and $20 \mathrm{~mm}$ high. The powder used for Laser Cladding is Inconel 718 with particle diameter lying between $45-105 \mu \mathrm{m}$, manufactured by gas atomization by ARCAM. The samples were manufactured on a Laser Cladding BeAM Mobile machine [37]. This machine is equipped with a coaxial nozzle including a powder jet, a local inerting argon flow and a fiber laser with a wavelength $1070 \mathrm{~nm}$ and a spot diameter of $0.75 \mathrm{~mm}$.

The process parameters were kept identical for all samples: laser speed $(2000 \mathrm{~mm} / \mathrm{min}=33.3 \mathrm{~mm} / \mathrm{s})$, laser power $(250 \mathrm{~W})$, powder mass flow $(6 \mathrm{~g} / \mathrm{min}=100 \mathrm{mg} / \mathrm{s})$, vertical increment between two layers $(0.2 \mathrm{~mm})$, back and forth motion of the nozzle. Two types of walls were manufactured:

(a) without any dwell time;

(b) with a 10 -second dwell time between two successive layers.

The defined process parameters and the specimen geometry conducted to a writing time of a single laser path of $2.7 \mathrm{~s}$. Therefore, the applied dwell time of 10 seconds added a significant cooling time between two successive layer depositions.

No heat treatment was applied to the samples after manufacturing.

The tensile specimen were finally water-jet cut in the bi-material wall. The interface is located in the center of the gauge section and is orthogonal to the loading direction of the tensile test. No geometrical distortion was noticed during or after the cutting process, indicating that the residual stresses induced by manufacturing were inferior to a buckling threshold.

The surface of the samples was mechanically polished up to $1 \mu \mathrm{m}$ before ion polishing in a Gatan PECS II machine to perform Electron BackScatter Diffraction and micro-hardness measurements. Vickers hardness was measured on an Innovastest Falcon 400 by applying $1.96 \mathrm{~N}$ during 10 seconds.

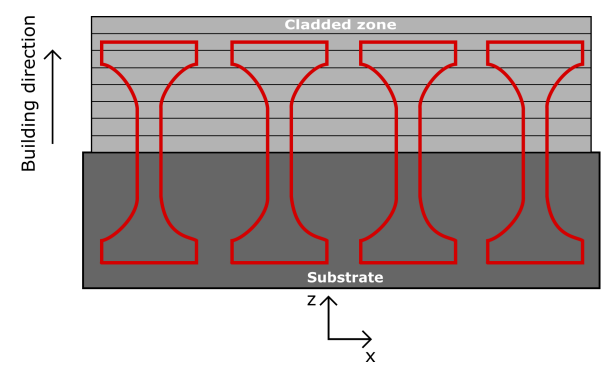

(a) Face view.

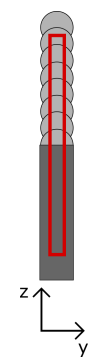

(b) Transverse section.

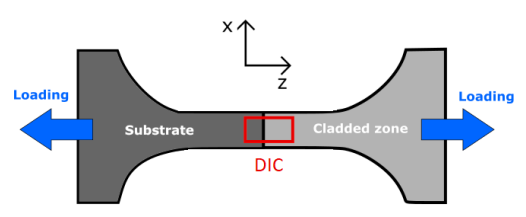

(c) Loading of tensile specimen.

Figure 1: Geometry of the repaired specimen and loading configuration.

\subsection{EBSD analysis}

The Scanning Electron Microscope (SEM) used in this study both for the Electron BackScatter Diffraction (EBSD) analysis and the in-situ tensile tests was a FEI Quanta 600 FEG-ESEM.

The EBSD maps were acquired using the Aztec software with a step size of $1 \mu \mathrm{m}$ on two planes of observations: face view and transverse section of the repaired structures as they are described in Fig. 1. The data was then analyzed with Channel 5 software to plot EBSD maps. The identification of each grains was obtained after imposing a disorientation threshold of $10^{\circ}$. 


\subsection{SEM in-situ tensile tests}

A gold grid with a $3 \mu \mathrm{m}$ pitch was then deposited by electro-lithography on the face view of the specimen in the interface area. The SEM in-situ tests were performed on a homemade tensile machine, they were displacement-controlled at $0.002 \mathrm{~mm} / \mathrm{s}$ and several loading steps with increasing amplitudes were applied. For each step, the sample is loaded until a chosen displacement, it is then unloaded and maintained at $20 \mathrm{~N}$ during the acquisition of the grid images for DIC to avoid creep.

Comparing the images for each step to an initial image of the grid gives access to the displacement field on the unloaded sample from which the strain field is derived. It is then assumed that there are no residual elastic strain field in the samples and that the main cause for incompatibility is plasticity. Consequently, since no image could be acquired on a loaded specimen, this protocol only enables to map plastic strains and not the total strains endured by the loaded sample.

\subsection{Results post-processing}

The data from the in-situ tests were first post-processed using the Digital Image Correlation software Correlation Manual Value [28, 38]. It enabled to compute strain maps with the integration scheme displayed in Fig. 2.

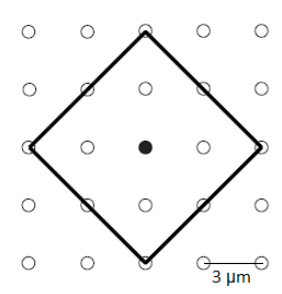

Figure 2: Integration scheme used for digital image correlation [38].

The strain maps were then superimposed to the grain maps obtained by EBSD by making coincide remarkable points of the microstructure. Detection of the grain contours was conducted with a Matlab code and the DIC points were sorted depending on which grains they belong to, similarly to what was done in [35]. It was then possible to derive average values per grain of displacement or strains and their standard deviation, as it will be shown in Sect. 3.5.

\section{Results}

The main results of this study are presented in this section. First, the EBSD maps are commented in Sect. 3.1. In Sect. 3.2, material properties extracted from the tensile tests are presented. The results from the micro-hardness measurements are also displayed and commented. Then, the strain maps from the SEM in-situ tensile tests are analyzed in Sect. 3.3. The Sect. 3.4 contains the failure analysis of the tested samples. In Sect. 3.5, additional maps are exhibited where average values per grain are displayed along an orthogonal path to the interface. The plotted evolution justifies the rationale behind the plastic strain distributions. Finally, Sect. 3.6 discusses a simplified one-dimensional numerical study on grain size effect of the Hall-Petch class and compares its prediction with the observations.

\subsection{EBSD analysis}

The conducted EBSD analysis are displayed in Fig. 3. The grain morphology is described by its aspect ratio, which is defined as the ratio of principal axes of the ellipse best correlated with the grain and with same surface. An equiaxed grain has an aspect ratio close to 1 . The substrate appears to be composed of small equiaxed grains randomly oriented (average size $20 \mu \mathrm{m}$ ) whereas the cladded deposit however has a much more specific microstructure. 


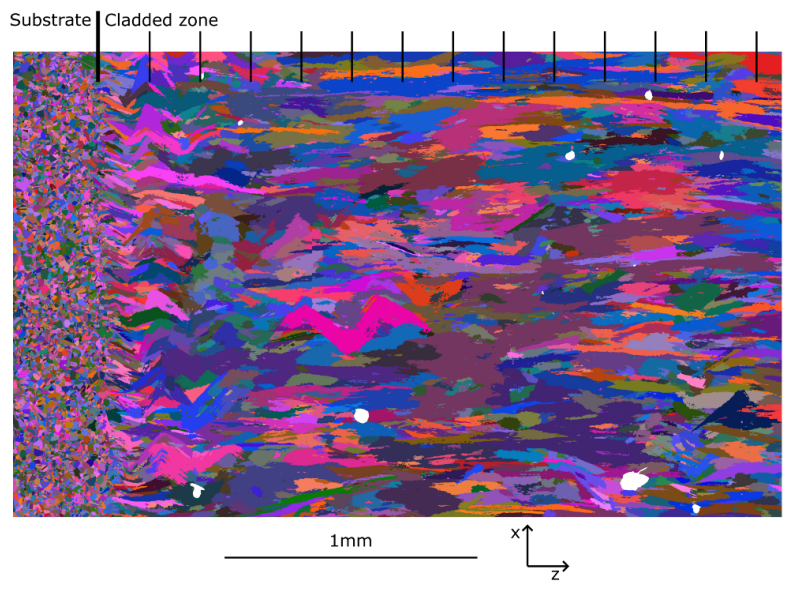

(a) Dwell time: 0s - Face view.

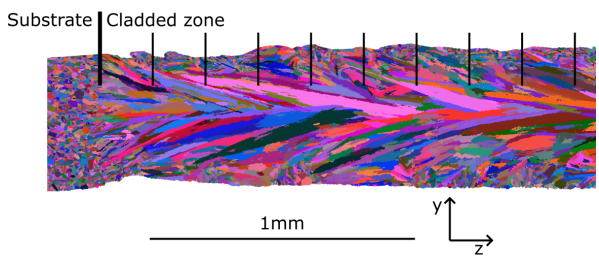

(c) Dwell time: 0s - Transverse section.

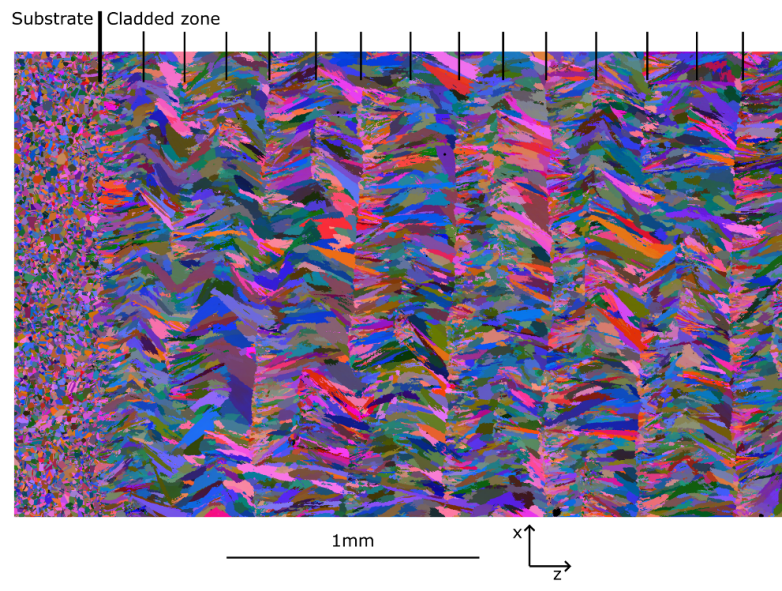

(b) Dwell time: 10s - Face view.

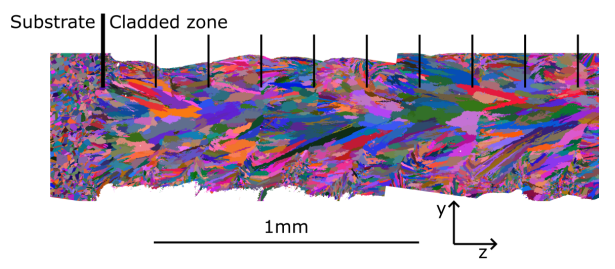

(d) Dwell time: 10s - Transverse section.

Figure 3: Differences of the microstructures obtained without (a) (c) and with (b) (d) dwell time. The RGB colour is affected to a grain depending on the value of its three Euler angles.

\subsubsection{Plane view EBSD maps}

For the specimen manufactured without dwell time, the microstructure of the deposited material consists of large columnar grains. The grain sizing up up to $1 \mathrm{~mm}$ length are impressive, when compared with the height of the deposited layers $(0.2 \mathrm{~mm})$. The columnar shape is characterized by an average aspect ratio close to 4 . It is important to remark that the process layers cannot be easily distinguished in the grain map. One can also notice that there is a transition zone between the substrate and the cladded region composed of smaller columnar grains, where a herringbone pattern along the layers can be distinguished. The patterns of this microstructure are similar to the one reported in [8] for high-power process parameters.

If a dwell time of 10 seconds is added between the deposition of two succesive layers during manufacturing, then the final microstructure of the repaired components exhibits completely different patterns as shown in Fig. 3b. The successive deposition layers can easily be identified and the complete cladded deposit zone presents a herringbone pattern assembled of columnar grains with an average aspect ratio of 2.5.

\subsubsection{Transverse section EBSD maps}

Fig. 3c and 3d reveal the EBSD maps of the transverse section in the absence and presence of dwell time, respectively. On both maps, one can notice a fine layer of $80 \mu \mathrm{m}$ depth close to the outer surfaces of the wall. The kernel region of the wall present significantly larger grains. This variation of microstructure along the wall thickness could be explained by different cooling mechanisms: near the surface, convection dominates whereas in the central part, the majority of the flux is conducted by conduction thanks to the substrate thermal pumping [39].

The influence of dwell time is still visible on the transverse section since the layers cannot be identified on the specimen manufactured without dwell time but they are visible on the 10-second dwell time specimen. 


\subsection{Tensile properties and micro-hardness}

Tensile properties extracted from the tests are gathered in Tab. 1. This data should be considered cautiously since only one specimen was tested for each category, whereas the dispersion from one sample to the other can be high. However, both yield stress and ultimate tensile stress are much lower for repaired specimens compared to the wrought material used as substrate. This result matches other work of the literature which have found that the tensile properties of the repaired specimens lies between the properties of the substrate and the additively manufactured material $[26,40]$.

\begin{tabular}{|r|r|c|c|}
\hline \multicolumn{2}{|c|}{} & Yield stress & Ultimate tensile stress \\
\hline \multicolumn{2}{|c|}{ Wrought Inconel 718 (substrate) } & $1012 \mathrm{MPa}$ & $1260 \mathrm{MPa}$ \\
\hline \multirow{2}{*}{ Repaired specimen } & No dwell time & $390 \mathrm{MPa}$ & $740 \mathrm{MPa}$ \\
& 10 -second dwell time & $510 \mathrm{MPa}$ & $880 \mathrm{MPa}$ \\
\hline
\end{tabular}

Table 1: Tensile properties

The evolution of micro-hardness along a line perpendicular to the interface was measured on both specimens. The results are displayed in Fig. 4. The wrought substrate has a mean hardness of $460 \mathrm{HV}$. Far from the interface, the cladded part exhibits a much lower hardness, around $270 \mathrm{HV}$ in average, regardless of dwell time. This micro-hardness profile is similar to comparable studies of the literature performed on laser cladded Inconel 718 [41].

In the sample manufactured with a 10-second dwell time, the first three layers seem to ensure a smoother transition with hardness around $300 \mathrm{HV}$. It is nevertheless difficult to notice a clear difference between those three layers and the rest of the microstructure on the EBSD maps of Fig. 3b and 3d. The precision of the experimental device does not offer the opportunity to make several measurements within one layer to compare the hardness at the interlayer where cluster of small grains can be observed.

Finally, it appears that the Heat Affected Zone (HAZ) is deeper for the specimen manufactured without dwell time than for the other one. Indeed, the component gets warmer during manufacturing so isothermal lines deepens in the substrate and a larger part of the substrate is affected metallurgically.

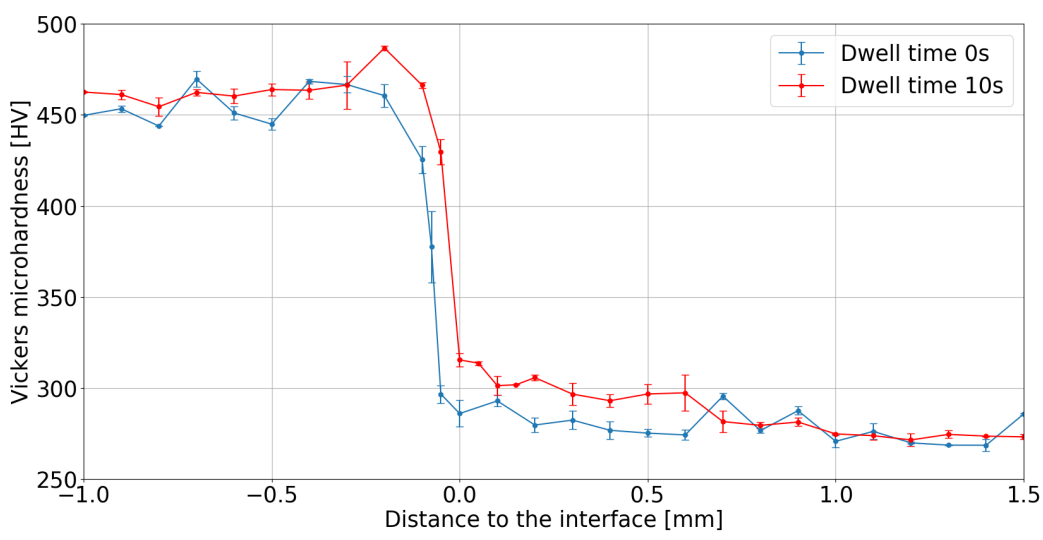

Figure 4: Evolution of Vickers micro-hardness across the interface.

\subsection{Strain maps}

The local spatial distribution of the plastic strain at the grain level in the repaired samples are displayed in Fig. 5 and 6. The two figures correspond to the absence or presence of dwell time during their manufacturing 
respectively. More specifically, Fig. 5 shows the evolution of the plastic strain component $\varepsilon_{p}^{z z}$ as the loading increases, while Fig. 6 displays the other plastic strain components $\varepsilon_{p}^{x z}$ and $\varepsilon_{p}^{x x}$ at the last loading step before failure.

The strain distribution is obviously not uniform along the sample, as one would expect in a bi-material component. One can conclude that strain localization occurs at two length scales:

(i) similarly to what was found at a macroscopic scale by Sui et al. in [30], the cladded region is much more plastically deformed than the substrate, which is particularly visible on $\varepsilon_{z z}$ map. Considering the yield strength is correlated with the hardness, this is consistent with the micro-hardness measurements displayed in Fig. 4.

(ii) in the repaired area, there is also a strain fluctuation at the grain size scale: strain varies within a grain or across a grain boundary. If it is hard to find any pattern in the specimen manufactured without dwell time, it is possible to see one emerge from the strain maps in the presence of dwell time. Indeed, with a 10-second dwell time, the highly strained location seems to follow the process layers, which corresponds to what was reported in [35] for additively manufactured 316 stainless steel with similar microstructure.

Furthermore, despite a uniaxial loading, the response of repaired specimen is locally multiaxial with a non zero shear component $\varepsilon_{x z}$ which can reach locally $15 \%$. This strong multiaxiality can activate other fracture modes than the mode I that would be expected for a uniaxial tension. Consquently, to apply a failure criterion on those repaired components, the multiaxiality of the response would have to be accounted for, even for a unixial loading, and multixial criteria such as the one proposed by Fatemi et al. in [42] would have to be used.

In the specimen manufactured without dwell time, two porosities can be noticed in the repaired region as exhibited in the left side of Fig. 5 and 6 . They are both spherical and their diameter are respectively 40 and $60 \mu \mathrm{m}$. Spherical porosities which are common in additive manufactured material are due to gas trapped at solidification [8]. The strain pattern observed around them is similar to the characteristic strain distribution around a circular hole in tension. This strain concentration appears to be limited to a zone of $150 \mu m$ centered on the porosity.

\subsection{Failure analysis}

On the specimen manufactured without dwell time, failure occured in the cladded zone at $0.3 \mathrm{~mm}$ of the interface. A fractography analysis of failure location was conducted with SEM secondary electrons imaging resulting in the pictures displayed in Fig. 7. They reveal the presence in the plane of failure of a sharpedged porosity with a maximum chord length of $30 \mu \mathrm{m}$. Dimples can be observed in Fig. 7 highlighting the ductile fracture of the sample. Those images also show the topography of the failed specimen, exhibiting the out-of-plane deformation of the laser cladded region. By correlating the strain map of Fig. $5 \mathrm{~d}$ and the failure location, it is possible to see that the failure location actually corresponds to the high plastic strain zone highlighted by a black rectangle.

In the specimen manufactured with a 10-second dwell time, the failure location was not in the gauge section but near the heads of the specimen, outside of the DIC zone. Therefore no information on the strain levels at failure location are available. The analysis of the failure location reveals that the initiation site is on the edge of the specimen. It is consequently hard to state if the initiation occured on a defect specific to laser cladding or on a defect introduced by waterjet cutting. 


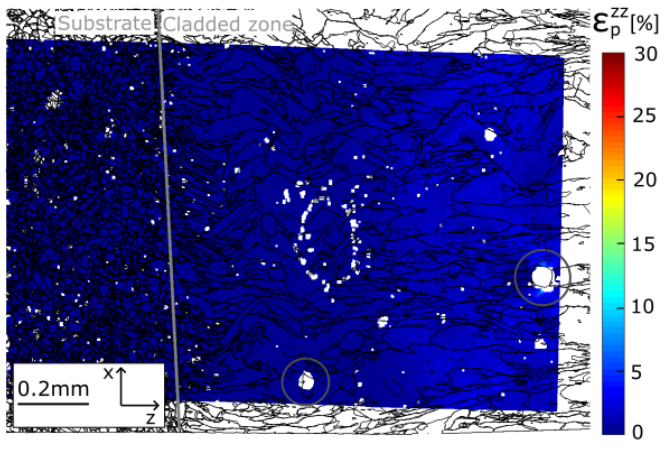

(a) Dwell time: $0 \mathrm{~s}-\varepsilon_{p}^{z z}$ at $37 \%$ of failure elongation

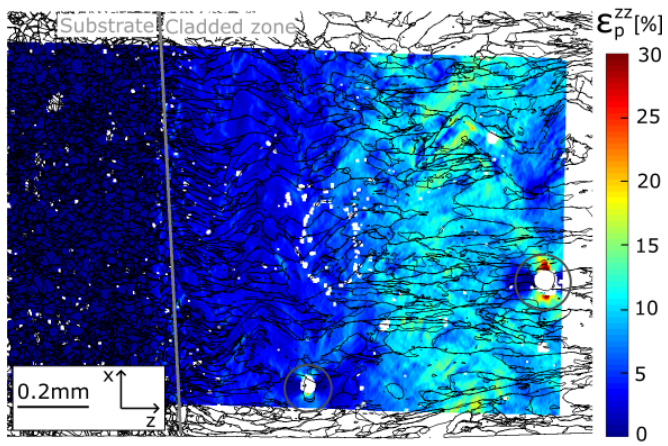

(b) Dwell time: $0 \mathrm{~s}-\varepsilon_{p}^{z z}$ at $68 \%$ of failure elongation

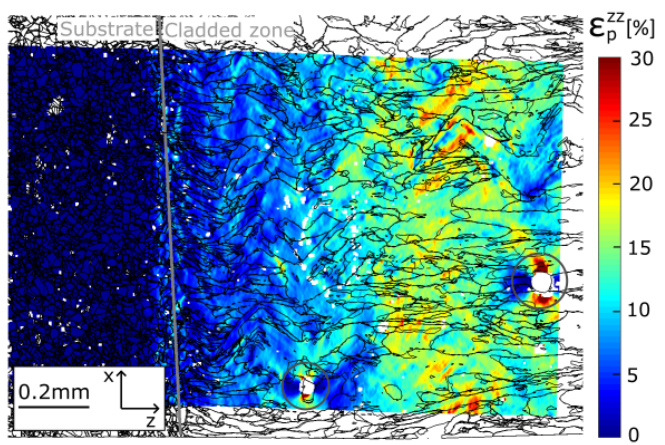

(c) Dwell time: $0 \mathrm{~s}-\varepsilon_{p}^{z z}$ at $84 \%$ of failure elongation

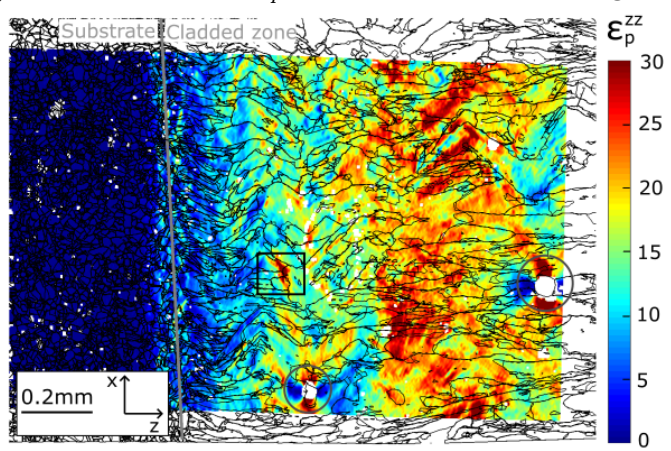

(d) Dwell time: $0 \mathrm{~s}-\varepsilon_{p}^{z z}$ at $99 \%$ of failure elongation

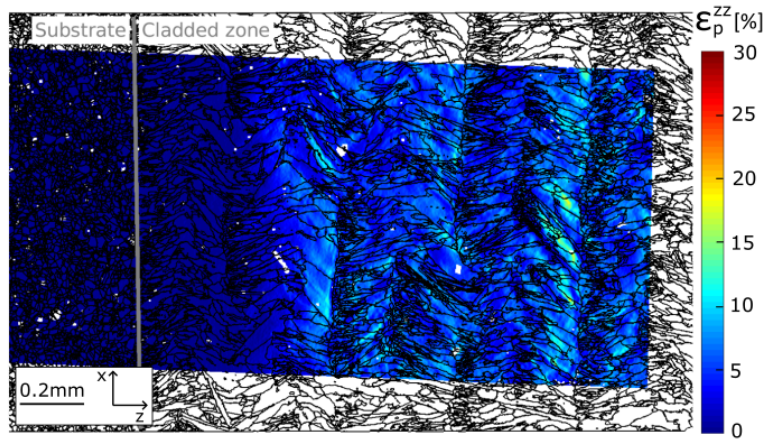

(e) Dwell time: $10 \mathrm{~s}-\varepsilon_{p}^{z z}$ at $50 \%$ of failure elongation



(f) Dwell time: $10 \mathrm{~s}-\varepsilon_{p}^{z z}$ at $65 \%$ of failure elongation

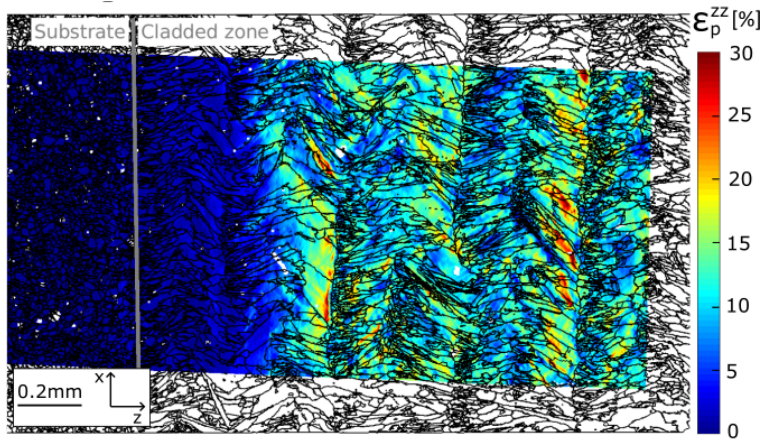

(g) Dwell time: $10 \mathrm{~s}-\varepsilon_{p}^{z z}$ at $82 \%$ of failure elongation

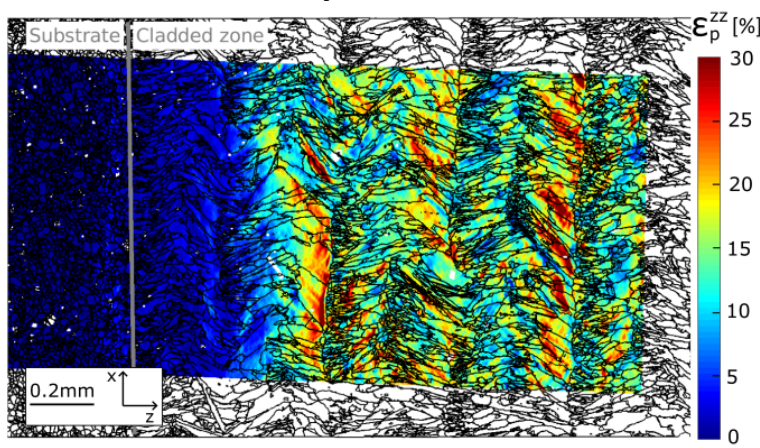

(h) Dwell time: $10 \mathrm{~s}-\varepsilon_{p}^{z z}$ at $98 \%$ of failure elongation

Figure 5: Evolution of plastic strain in the specimen without dwell time (a), (b), (c), (d) and in the specimen with a 10-second dwell time (e), (f), (g), (h). In the specimen manufactured without dwell time, the grey circles highlight the porosities found in the observed planes and the black rectangle locates failure location. 


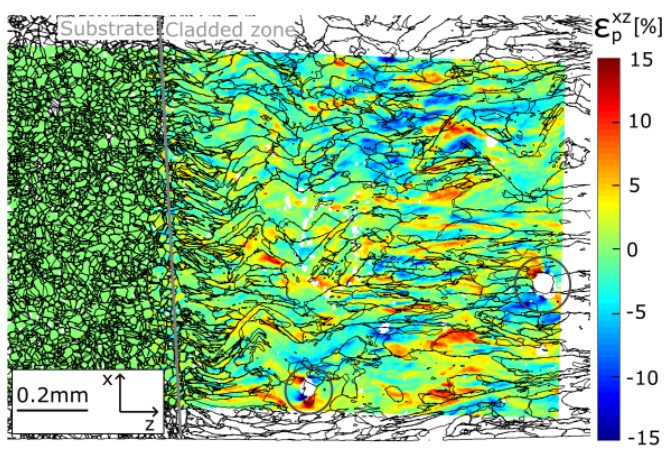

(a) Dwell time: $0 \mathrm{~s}-\varepsilon_{p}^{x z}$ at $99 \%$ of failure elongation

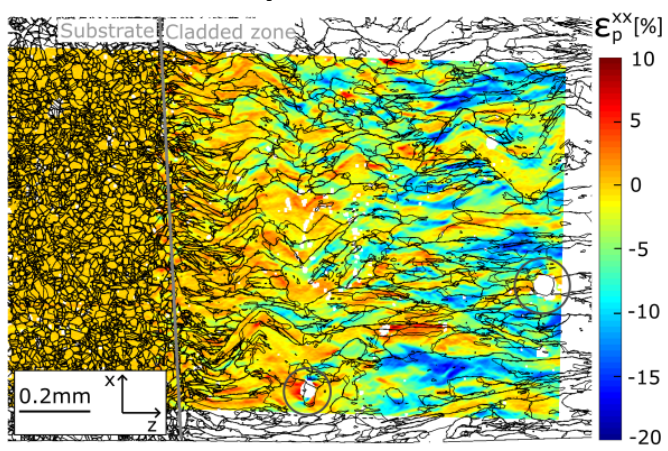

(b) Dwell time: $0 \mathrm{~s}-\varepsilon_{p}^{x x}$ at $99 \%$ of failure elongation

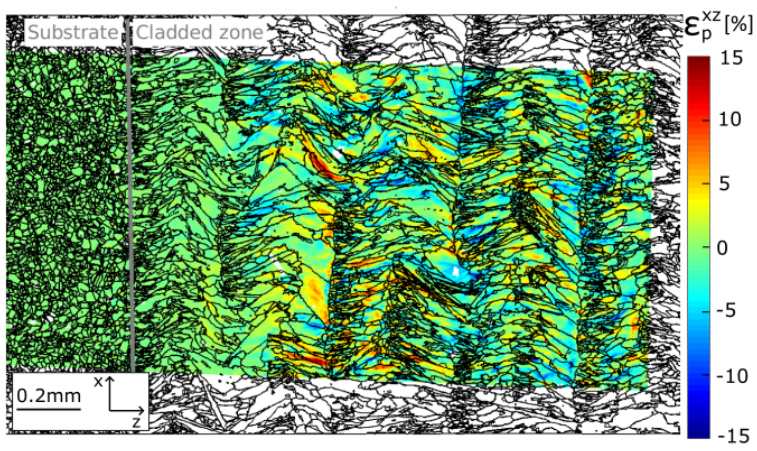

(c) Dwell time: $10 \mathrm{~s}-\varepsilon_{p}^{x z}$ at $98 \%$ of failure elongation

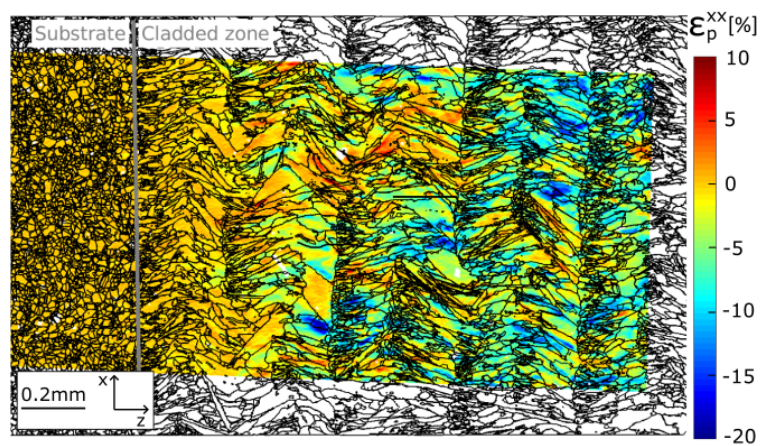

(d) Dwell time: $10 \mathrm{~s}-\varepsilon_{p}^{x x}$ at $98 \%$ of failure elongation

Figure 6: Multiaxiality of plastic strain in the specimen without dwell time (a), (b) and in the specimen with a 10-second dwell time (c), (d).

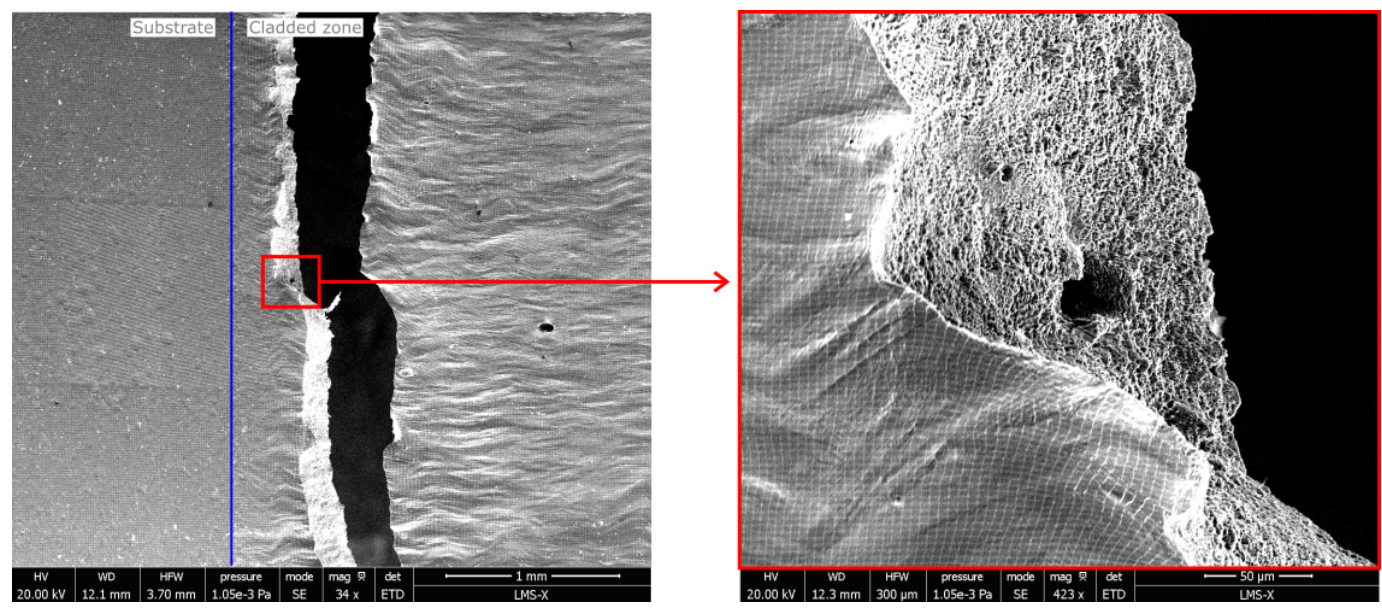

Figure 7: SEM Fractography analysis of the specimen manufactured without dwell time revealing a sharpededge porosity of $30 \mu m$ at failure location. 


\subsection{Average per grain}

From the previous observations, the following question arises naturally: why does the cladded region deform more than the substrate? To investigate this issue, we have to extract further quantitative information from the superimposition of the grain contours and the strain maps than the one displayed in Fig. 5 and 6 .

The contour detection method described in subsection 2.4 enabled to affect every DIC point to the grain it belonged to. Therefore we could access the average and the standard deviation of the strains measured in each grain. The maps presenting the average value of $\varepsilon_{p}^{z z}$ and the corresponding coefficients of variation, i.e. standard deviation divided by mean value, in each grains are plotted in Fig. 8.

One can remark, that several grains present a high coefficient of variation. Let us further notice that over the substrate or within grains where there plastic strains are small, signal to noise ratio is small and precise observations are difficult. In the vicinity of porosities, one distinguishes that the main localization pattern depends on the precise morphology of the porosity independently of the particular microstucture surrounding it. Moreover, the coefficient of variation is almost everywhere smaller than $25 \%$, a reasonably small value, which corroborates that the maps plotting average strain per grain can be used in confidence to analyze the major features of plastic strain localization.

The micro-hardness measurements conducted on both specimens indicate that the substrate is much harder than the cladded part. This indicates that the yield stress of the repaired region should be lower than the one in the wrought material [41]. Indeed, the first striking aspect is that the grains of the substrate are significantly less deformed than the grains of the cladded region. This strain localization could be caused by several phenomena: chemical segregations, sub-grain structure (dendrites), grain size, morphology or orientation [34].

First, the fact that plastic strain is larger in the cladded region could be explained by a dominant grain orientation favorable to the activation of slip planes. A map of the Schmid factor of each specimen appears in Fig. 9. It is true that in average the Schmid factor is slightly lower in the substrate (0.45) than it is in the repaired area (0.47). However, the grains with the higher strain levels are not the one with the higher Schmid factor. Consequently, the orientation of grains might not be responsible for the large scale pattern of strain localization. However, it can still be at the origin of small strain variations at the lower scale, i.e. from one grain to another.

Second, the other rationale is that the main cause for strain distribution at the observed scale is a grain size effect. The dislocations involved in plasticity are stopped or slowed down by grain boundaries. In polycristals, this mechanism is referred to as the Hall-Petch effect [43, 44]: the smaller the grains, the higher the yield stress. The grains boundaries obtained by EBSD highlight the big differences in grain surface between the original plate (less than $\left.100 \mu \mathrm{m}^{2}\right)$ and the cladded region $\left(1800 \mu \mathrm{m}^{2}\right.$ in average for the specimen without dwell time and $500 \mu^{2}$ with a 10-second dwell time).

Moreover, on the specimen manufactured with a 10-second dwell time, one can notice that the strain localization pattern followed the pattern of the layer. If we take a closer look to Fig. 8c, the grains with higher strains are large grains located just next to small grains clusters. Due to the high number of grains boundaries in those clusters, these small areas experience less plastic strain than the large grains in their immediate vicinity.

The part played by the grain size effect in the plastic distribution at large scale in repaired components will be analyzed more thoroughly in the next section.

\subsection{Grain size effect}

The grain size effect in metals is well known and is often referred to as Hall-Petch effect, from the work of Hall [43] and Petch [44]. They have observed that for specimen with equiaxed grains of different homogeneous size, the yield stress depends on average grain size as follows

$$
\sigma_{y}=\sigma_{0}+\frac{k}{\sqrt{d}}
$$

where $\sigma_{0}$ is yield strength of a single crystal and corresponds to the resistance of the lattice to dislocation motion, $k$ is the strengthening coefficient specific to each material and $d$ is the average grain diameter. 


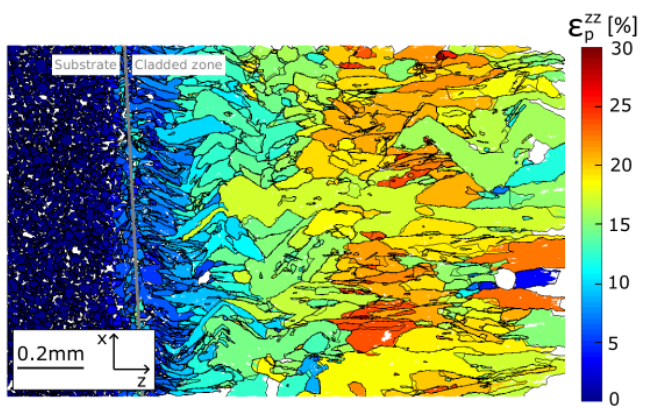

(a) Dwell time: 0s - Average of $\varepsilon_{p}^{z z}$ at $99 \%$ of failure elongation.

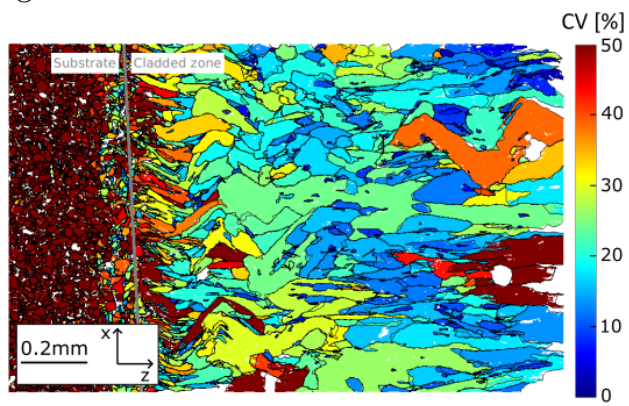

(b) Dwell time: 0s - Coefficient of variation of $\varepsilon_{p}^{z z}$ at $99 \%$ of failure elongation.

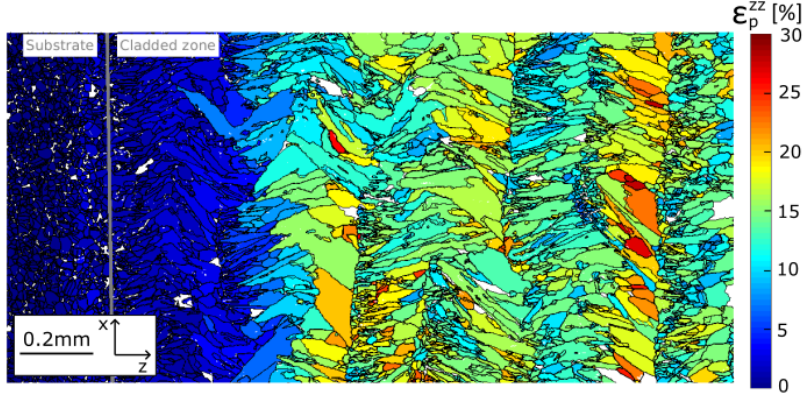

(c) Dwell time: 10s - Average of $\varepsilon_{p}^{z z}$ at $98 \%$ of failure elongation.

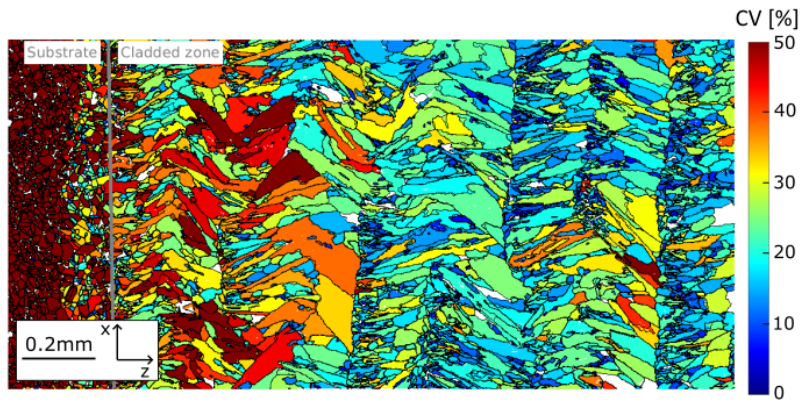

(d) Dwell time: $10 \mathrm{~s}$ - Coefficient of variation of $\varepsilon_{p}^{z z}$ at $99 \%$ of failure elongation.

Figure 8: Average and standard deviation of plastic strain component $\varepsilon_{p}^{z z}$ derived for each grain in the specimen without dwell time (a), (b) and in the specimen with a 10-second dwell time (c), (d).

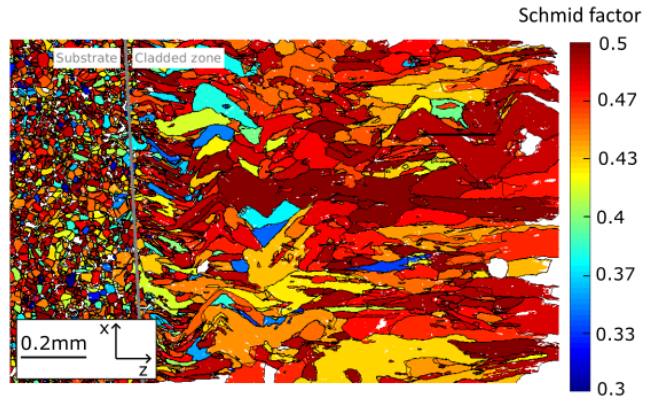

(a) Dwell time: 0s - Schmid factor.

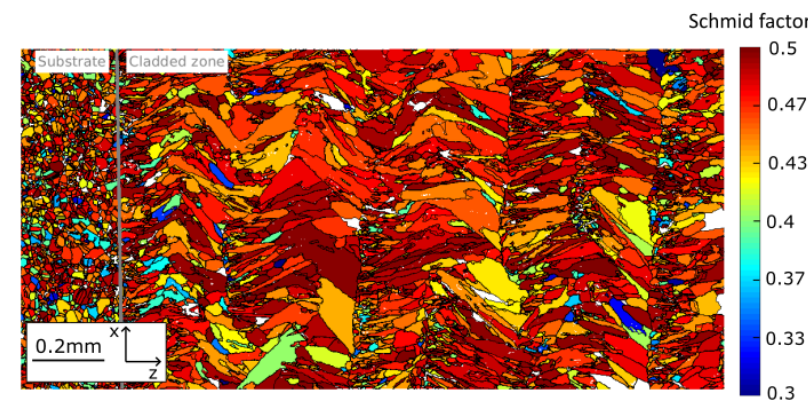

(b) Dwell time: 10s - Schmid factor.

Figure 9: Schmid factor derived from grain orientations and loading direction in the specimen without dwell time (a) and in the specimen with a 10-second dwell time (b).

In a polycrystal, grain boundaries are obstacles for dislocations motion and the stress which builds up in the neighboring grain depend on the number of dislocations within a grain. This will eventually activate dislocation sources and thus enabling deformation also in the adjacent grain. Therefore, the grain size influences how many dislocations piles up at the grain boundary and consequently affects the yield strength of the polycrystal.

In these samples exhibiting a microstructural gradient, the objective is to check if a grain size effect could explain the general observation that the substrate experiences less plastic strain than the cladded region.

Initially, the Hall-Petch law was designed to compare yield strength of samples with homogeneous grain size. However, some authors have tried to use it in the presence of a microstructural gradient with interesting 
results when the length scale of the microstructure variation was small comparing to the localization pattern $[10,45]$.

In the specimen obtained in the absence of dwell time, the increasing size of grains from the substrate to the cladded region is regular and no small scale localization pattern was observed. However, in the specimen manufactured with a 10 -second dwell time, it is impossible to introduce a grain size effect using only HallPetch law due to the cluster of small grains located at the interlayers. The microstructural gradient follows a more complicated pattern and this structural effect should be investigated numerically with tools such as crystal plasticity.

Consequently, in what follows, only the case of plastic strain distribution in the specimen without dwell time is investigated with a one-dimensional Finite Element Analysis realized with Z-set software [46]. A regular mesh of 100 beam elements of $10 \mu \mathrm{m}$ was built representing a zone of $1 \mathrm{~mm}$ across the interface. An elasto-plastic behavior with linear isotropic hardening is assigned to the elements. The constitutive equations of state variables are the following [47]:

$$
\begin{array}{lrl}
\text { Elastic stress-strain relationship } & \sigma & =E\left(\varepsilon-\varepsilon^{p}\right) \\
\text { Flow rule and isotropic hardening law } & \dot{\varepsilon}^{p} & =\gamma \operatorname{sign}(\sigma), \quad \dot{\alpha}=\gamma \\
& f(\sigma, \alpha) & =|\sigma|-\left(\sigma_{y}+K \alpha\right) \leq 0 .
\end{array}
$$

where $E$ is the Young modulus, $\sigma_{y}$ the yield stress and $K$ the plastic modulus.

The material parameters of this model are chosen to meet the classical characteristics of Inconel 718 [36]: $E=200 G P a, K=2500 M P a$ and the yield stress follows Hall-Petch relation recalled in Eq. 1 with the smoothed grain size factor of Fig. 10a and $\sigma_{0}$ depending on $k$ to retrieve a substrate yield strength of $1012 M P a[36]$.

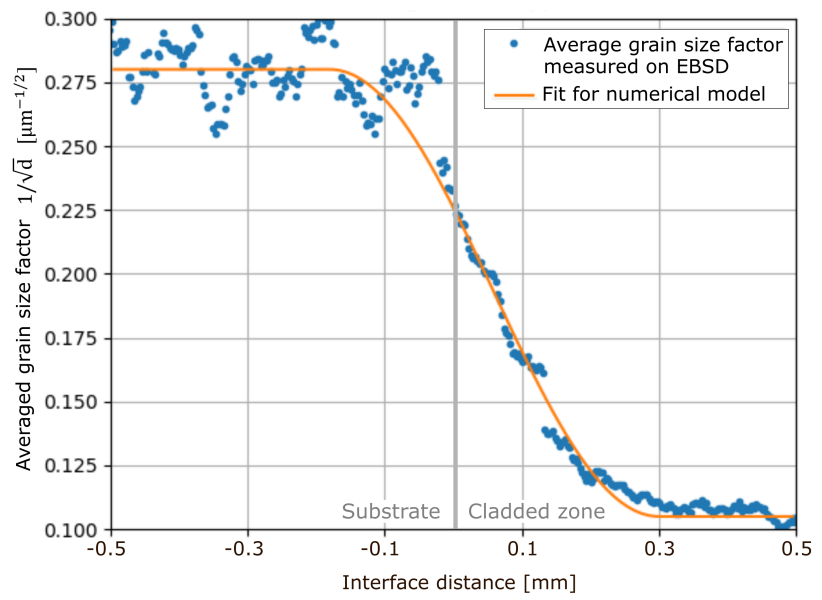

(a) Grain size evolution

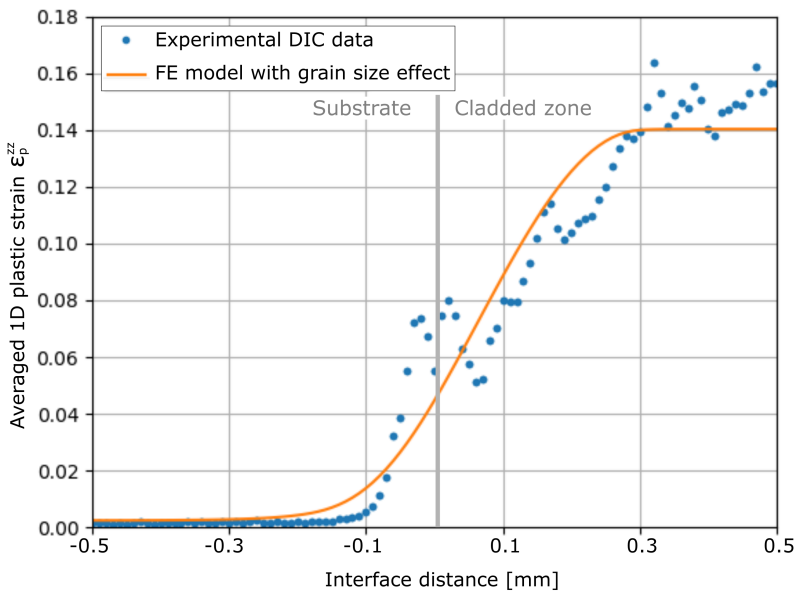

(b) Plastic strain.

Figure 10: Grain size effect in the specimen without dwell time.

The two dimensional plastic strain map of Fig. 5d is projected in one dimension by averaging along the $\mathrm{x}$ direction. This provides the experimental plastic strain and grain size factor as a function of the distance to the interface. The grain size factor $d$ is the average grain diameter, it is computed as the diameter of a disk whose surface is the same as the grain. This projection leads to the blue points curve displayed on Fig. 10.

As one can notice on Fig. 10a, the grain size factor average is very irregular which could lead to numerical instabilities. It was then smoothed into the orange curve on Fig. 10a which will be used as the grain size factor for the numerical model.

Then, the strengthening coefficient $k$ of Eq. 1 is determined by optimization using Nelder-Mead Simplex algorithm [48]. More specifically, we minimize the $\mathrm{L}^{2}$ norm of the difference between the one-dimensional 
average plastic strain experimental data from DIC and the one-dimensional plastic strain derived by FEM. The optimization converges easily to a global minimum $k=2.0 \mathrm{MPa} / \mu \mathrm{m}^{1 / 2}$.

The graph of Fig. 10b displays the result of the minimization of error between experimental and numerical results. The numerical strain (orange curve) seems to follow the overall variation of experimental plastic strain (blue points) across the microstructural gradient. The slope and plateaux are pretty well captured but it is not the case for the small scale variation. Two explanations can be put forward. First, small scale heterogeneity like porosities or precipitates have an impact on the strain distribution. The averaging along the $\mathrm{x}$ direction that was performed here mitigates the effect of precipitates and porosities but does not erase it completely. Second, grain morphology or grain orientation should be also modeled to reproduce the complete microstructure, using polycrystal plasticity for instance.

\section{Discussion}

In this last section, we would like share with the readers a few comments about the specificity of this work and its limit.

\subsection{D observations on a $3 D$ structure}

As explained in Sec. 2.2, the in-situ tensile tests gave only access to the strain maps on the specimen face view. However, the EBSD observations of the transverse section displayed in Fig. 3c and 3d prove that the microstructure is far from being homogeneous along the thickness of the samples. Due to material removal for polishing, the face view plane we observe is actually located in the center of the wall transverse section, where the grains are the larger. It could be of major interest to model the small grains layer which lies opposite to the observed plane during in-situ testing and to investigate its influence on plastic strain distribution.

Consequently, the fact that we try to explain plastic strain localization in the three-dimensional repaired structure only by looking at 2D strain maps is a clear limitation of the present work. Conducting 3D EBSD analysis, looking at the strain in the transverse section or realizing a full three-dimensional FEM model could be ways to deal with this issue.

\subsection{Use of Inconel 718 without precipitation hardening}

Inconel 718 is a nickel alloy which is generally used in its aged form. This aging is performed by heat treatment consisting in the following steps [36]:

- annealing at $1000^{\circ} \mathrm{C}$ for 1 hour, followed by rapid cooling, usually water cooling;

- precipitation hardening at around $750^{\circ} \mathrm{C}$ for 10 hours;

- precipitation hardening at $650^{\circ} \mathrm{C}$ for another 10 hours, followed by air cooling.

Indeed, in this aged form the precipitation of $\gamma^{\prime \prime}$ phase $\left(\mathrm{Ni}_{3} \mathrm{Nb}\right)$ offers a strong hardening and modifies the behavior of the microstructure and the material.

In this study, no heat treatment was applied as the repaired structures after manufacturing. Therefore, $\gamma^{\prime \prime}$ precipitates are not found neither in the substrate nor in the repaired region. The goal of the present work was to investigate the effect of the spatial gradient of the microstructure in a repaired structure. If precipitation hardening would have been performed, the yield stress, and consequently the plastic strain distribution, would have been driven by the size and density of the $\gamma^{\prime \prime}$ precipitates and no longer by the size, morphology or orientation of grains as it was proven here.

As such, this work is only a preliminary study mainly focused on the impact of microstructural gradient and it is therefore distant from industrial applications on real components where usually a precipitation hardening is performed. 


\subsection{Laves phases}

Inconel 718 is a nickel alloy in which Laves phase can precipitate due to chemical segregation during cooling. This metallurgical phase is undesirable because it reduces ductility and tensile resistance [49]. All authors in the literature agree on the fact that additively manufactured parts contains these Laves phases that can be partially removed by performing a heat treatment $[8,30,50,51]$.

In [30], Sui et al. could observe that when submitted to loading, the Laves phases, which are more fragile, are submitted to stress concentration and eventually break. They consequently play a big role in failure and damage mechanisms. However, the work of Sui et al. were conducted on massive cladded components with complex microstructure and the grain size gradient between the substrate and the repaired region is less pronounced than in this study with single-track walls. To be able to observe a large zone across the interface $(1 \mathrm{~mm} \times 2 \mathrm{~mm})$, the pattern on which DIC was performed is a grid with a $3 \mu \mathrm{m}$ pitch. With the integration scheme displayed in Fig.2, the average strain is derived on a $8.5 \mu \mathrm{m}$ square. This precision does not enable us to actually observe the strain pattern induced around Laves phase due to stress concentration. To do so, performing very high resolution DIC would be needed with patterns of characteristic size around hundred of nanometers $[32,52]$. Even if the observation zone would have been too small to observe the structural effect of the interface between the substrate and the repaired area, this technique could provide information at the scale of Laves and is a promising perspective to the present work.

\section{Conclusion}

This experimental work has highlighted that the Inconel 718 components repaired using the Laser Cladding technology exhibit a strong spatial gradient of microstructure. In the interface region, the microstructure evolves from the small equiaxed grains of the substrate to larger columnar grains. This gradient depends on the process parameters. Here, we investigated only the particular impact of the dwell time added between the printing of two successive layers. The dwell time affects the cooling rates during solidification and the temperature of the substrate layer during deposition. The observation demonstrated beyond doubt that the influence of dwell time is prominent, changing profoundly the pattern of the microstructure of the repaired region and leading to polycrystalline structures with remarkably different characteristics.

In-situ SEM uniaxial tensile tests have pointed out that the microstructural gradient induces a plastic strain localization in the cladded region. This can be explained on the large scale by grain size effect using the rationale of the Hall-Petch law, which states that larger grains exhibit a lower yield stress. In the present case, larger grains correspond to the repaired area, implying that the repaired area has a lower yield stress than the initial wrought substrate. However, the variation of the plastic strain distribution at a smaller scale involves more complex phenomena and interactions, porosities, precipitates... This effects could be modeled using crystal plasticity taking into account the price 3D geometry of the grain distribution as well as the presence of clusters of small grains, grain morphology and orientation, out-of-plane effects, etc. which is one of the perspectives of the study.

In order to extend the study to repaired components in industrial applications, it is necessary to take into account the additional heat treatments applied to parts and the subsequent microstructural modifications. Furthermore, the monotonic tensile experiments should be completed with cyclic test loading. Finally, further observations of the plastic and damage mechanisms could be provided by performing very high resolution DIC, investigating the role of Laves phases in order to estimate their impact on fatigue lifetime.

\section{Acknowledgment}

The authors would like to thank Direction Générale de l'Armement, France for the funding of the BeAM Mobile Laser Cladding machine at Ecole polytechnique - ENSTA used in this study. The FEG SEM FEI Quanta 600 has been acquired with the financial support of Région Ile-de-France (SESAME 2004 program), CNRS and Ecole polytechnique. The authors would also like to acknowledge the help of Matthieu Roy from Laboratoire Leprince-Ringuet, Ecole Polytechnique, France for the water-cutting of the specimen. 


\section{References}

[1] J. Michael Wilson, Cecil Piya, Yung C. Shin, Fu Zhao, and Karthik Ramani. Remanufacturing of turbine blades by laser direct deposition with its energy and environmental impact analysis. Journal of Cleaner Production, 80:170 - 178, 2014.

[2] T. DebRoy, H.L. Wei, J.S. Zuback, T. Mukherjee, J.W. Elmer, J.O. Milewski, A.M. Beese, A. Wilson-Heid, A. De, and W. Zhang. Additive manufacturing of metallic components - process, structure and properties. Progress in Materials Science, 92:112 - 224, 2018.

[3] Benjamin Graf, Andrey Gumenyuk, and Michael Rethmeier. Laser metal deposition as repair technology for stainless steel and titanium alloys. Physics Procedia, 39:376 - 381, 2012. Laser Assisted Net shape Engineering 7 (LANE 2012 ).

[4] Bonny Onuike and Amit Bandyopadhyay. Additive manufacturing in repair: Influence of processing parameters on properties of inconel 718. Materials Letters, 252:256 - 259, 2019.

[5] Yangyang Lei, Jun Xiong, and Rong Li. Effect of inter layer idle time on thermal behavior for multi-layer single-pass thinwalled parts in GMAW-based additive manufacturing. The International Journal of Advanced Manufacturing Technology, 96(1):1355-1365, Apr 2018.

[6] Y. Yang, M.F. Knol, F. van Keulen, and C. Ayas. A semi-analytical thermal modelling approach for selective laser melting. Additive Manufacturing, 21:284 - 297, 2018.

[7] Pavel Hanzl, Miroslav Zetek, Tomas Baksa, and Tomas Kroupa. The influence of processing parameters on the mechanical properties of SLM parts. Procedia Engineering, 100:1405 - 1413, 2015. 25th DAAAM International Symposium on Intelligent Manufacturing and Automation, 2014.

[8] Lakshmi L. Parimi, Ravi G. A., Daniel Clark, and Moataz M. Attallah. Microstructural and texture development in direct laser fabricated Inconel 718. Materials Characterization, 89:102 - 111, 2014.

[9] V. Ocelik, I. Furar, and J.Th.M. De Hosson. Microstructure and properties of laser clad coatings studied by orientation imaging microscopy. Acta Materialia, 58(20):6763 - 6772, 2010.

[10] Zhuqing Wang, Todd A. Palmer, and Allison M. Beese. Effect of processing parameters on microstructure and tensile properties of austenitic stainless steel 304L made by directed energy deposition additive manufacturing. Acta Materialia, 110:226 - 235, 2016.

11] Kangbo Yuan, Weiguo Guo, Penghui Li, Jianjun Wang, Yu Su, Xin Lin, and Yanping Li. Influence of process parameters and heat treatments on the microstructures and dynamic mechanical behaviors of Inconel 718 superalloy manufactured by laser metal deposition. Materials Science and Engineering: A, 721:215 - 225, 2018.

[12] Haider Ali, Hassan Ghadbeigi, and Kamran Mumtaz. Effect of scanning strategies on residual stress and mechanical properties of selective laser melted ti6al4v. Materials Science and Engineering: A, 712:175 - 187, 2018.

[13] Carolin Korner, Harald Helmer, Andreas Bauereiß, and Robert Singer. Tailoring the grain structure of IN718 during selective electron beam melting. MATEC Web of Conferences, 14:08001, 012014.

[14] H. L. Wei, J. Mazumder, and T. DebRoy. Evolution of solidification texture during additive manufacturing. Nature, 2015.

[15] Erik R. Denlinger, Jarred C. Heigel, Pan Michaleris, and T.A. Palmer. Effect of inter-layer dwell time on distortion and residual stress in additive manufacturing of titanium and nickel alloys. Journal of Materials Processing Technology, $215: 123-131,2015$.

[16] J.C. Heigel, P. Michaleris, and E.W. Reutzel. Thermo-mechanical model development and validation of directed energy deposition additive manufacturing of Ti-6Al-4V. Additive Manufacturing, 5:9 - 19, 2015.

[17] Nathan A. Kistler, David J. Corbin, Abdalla R. Nassar, Edward W. Reutzel, and Allison M. Beese. Effect of processing conditions on the microstructure, porosity, and mechanical properties of Ti-6Al-4V repair fabricated by directed energy deposition. Journal of Materials Processing Technology, 264:172 - 181, 2019.

[18] B. K. Foster, A. M. Beese, J. S. Keist, E. T. McHale, and T. A. Palmer. Impact of interlayer dwell time on microstructure and mechanical properties of nickel and titanium alloys. Metallurgical and Materials Transactions A, 48(9):4411-4422, Sep 2017.

[19] Guijun Bi and Andres Gasser. Restoration of nickel-base turbine blade knife-edges with controlled laser aided additive manufacturing. Physics Procedia, 12:402 - 409, 2011. Lasers in Manufacturing 2011 - Proceedings of the Sixth International WLT Conference on Lasers in Manufacturing.

[20] P.L. Blackwell. The mechanical and microstructural characteristics of laser-deposited Inconel 718. Journal of Materials Processing Technology, 170(1):240 - 246, 2005.

[21] Bei He, Xiang-Jun Tian, Xu Cheng, Jia Li, and Hua-Ming Wang. Effect of weld repair on microstructure and mechanical properties of laser additive manufactured Ti-55511 alloy. Materials \& Design, 119:437 - 445, 2017.

[22] H. Paydas, A. Mertens, R. Carrus, J. Lecomte-Beckers, and J. Tchoufang Tchuindjang. Laser cladding as repair technology for Ti-6Al-4V alloy: Influence of building strategy on microstructure and hardness. Materials 85 Design, 85:497 - 510, 2015.

[23] Ramesh Raju, Muthukannan Duraiselvam, Vijay Petley, Shweta Verma, and R. Rajendran. Microstructural and mechanical characterization of Ti6Al4V refurbished parts obtained by laser metal deposition. Materials Science and Engineering: A, 643:64-71, 2015.

[24] Jianli Song, Qilin Deng, Changyuan Chen, Dejin Hu, and Yongtang Li. Rebuilding of metal components with laser cladding forming. Applied Surface Science, 252(22):7934 - 7940, 2006.

[25] Lijun Song, Guangcheng Zeng, Hui Xiao, Xianfeng Xiao, and Simeng Li. Repair of 304 stainless steel by laser cladding with 316L stainless steel powders followed by laser surface alloying with WC powders. Journal of Manufacturing Processes, $24: 116-124,2016$

[26] Yanyan Zhu, Jia Li, Xiangjun Tian, Huaming Wang, and Dong Liu. Microstructure and mechanical properties of hybrid 
fabricated $\mathrm{Ti}-6.5 \mathrm{Al}-3.5 \mathrm{Mo}-1.5 \mathrm{Zr}-0.3 \mathrm{Si}$ titanium alloy by laser additive manufacturing. Materials Science and Engineering: A, 607:427 - 434, 2014.

[27] Pierre Baudoin. Caractérisation et identification de propriétés de matériaux métalliques à gradients de microstructure. PhD thesis, Université de Lille I, 2015.

[28] Pascal Doumalin and Michel Bornert. Micromechanical Applications of Digital Image Correlation Techniques, chapter Speckle Photography: Image Correlation Techniques, pages 67-74. Springer Berlin Heidelberg, Berlin, Heidelberg, 2000.

[29] Zhuang Zhao, Jing Chen, Qiang Zhang, Hua Tan, Xin Lin, and Wei dong Huang. Microstructure and mechanical properties of laser additive repaired Ti17 titanium alloy. Transactions of Nonferrous Metals Society of China, 27(12):2613 - 2621, 2017.

[30] Shang Sui, Jing Chen, Rui Zhang, Xianliang Ming, Fencheng Liu, and Xin Lin. The tensile deformation behavior of laser repaired inconel 718 with a non-uniform microstructure. Materials Science and Engineering: A, 688:480 - 487, 2017.

[31] Todd A. Book and Michael D. Sangid. Strain localization in Ti-6Al-4V Widmanstätten microstructures produced by additive manufacturing. Materials Characterization, 122:104 - 112, 2016.

[32] Joseph Marae Djouda, Yazid Madi, Fabrice Gaslain, Jérémie Beal, Jérôme Crépin, Guillaume Montay, Léa Le Joncour, Naman Recho, Benoit Panicaud, and Thomas Maurer. Investigation of nanoscale strains at the austenitic stainless steel 316L surface: Coupling between nanogauges gratings and EBSD technique during in situ tensile test. Materials Science and Engineering: A, 740-741:315 - 335, 2019.

[33] David Foehring, Huck Beng Chew, and John Lambros. Characterizing the tensile behavior of additively manufactured Ti-6Al-4V using multiscale digital image correlation. Materials Science and Engineering: A, 724:536 - 546, 2018.

[34] Yung Suk Jeremy Yoo, Todd A. Book, Michael D. Sangid, and Josh Kacher. Identifying strain localization and dislocation processes in fatigued Inconel 718 manufactured from selective laser melting. Materials Science and Engineering: A, $724: 444-451,2018$

[35] Yanis Balit, Eric Charkaluk, and Andrei Constantinescu. Digital image correlation for microstructural analysis of deformation pattern in additively manufactured 3161 thin walls. Additive Manufacturing, 2019.

[36] Special Metals. Inconel alloy 718. www.specialmetals.com, 2018.

[37] BeAM. Gamme de machines - mobile et modulo. http://www.beam-machines.fr/fr/produits, 2016.

[38] Michel Bornert. Morphologie microstructurale et comportement mécanique ; caractérisations expérimentales, approches par bornes et estimations autocohérentes généralisées. Theses, Ecole Nationale des Ponts et Chaussées, November 1996.

[39] Camille Guevenoux, Simon Hallais, Alexandre Charles, Eric Charkaluk, and Andrei Constantinescu. Influence of interlayer dwell time on the microstructure of Inconel 718 Laser Cladded components. submitted to Optics 83 Laser Technology, 2019.

[40] Yanis Balit, Camille Guévenoux, Manas V. Upadhyay, Eric Charkaluk, and Andrei Constantinescu. Digital image correlation for microstructural localisation analysis of ss3161 repaired by directed energy deposition. Submitted to Material Letters, 2020

[41] I. Tabernero, A. Lamikiz, S. Martínez, E. Ukar, and J. Figueras. Evaluation of the mechanical properties of Inconel 718 components built by laser cladding. International Journal of Machine Tools and Manufacture, 51(6):465 - 470, 2011.

[42] Ali Fatemi, Reza Molaei, Shahriar Sharifimehr, Nam Phan, and Nima Shamsaei. Multiaxial fatigue behavior of wrought and additive manufactured Ti-6Al-4V including surface finish effect. International Journal of Fatigue, 100:347 - 366, 2017.

[43] E O Hall. The deformation and ageing of mild steel: III discussion of results. Proceedings of the Physical Society. Section $B, 64(9): 747-753$, sep 1951.

[44] N.J. Petch. The cleavage strength of polycrystals. J. Iron Steel Inst., 174:25, 1953.

45] Pierre Baudoin, Vincent Magnier, Ahmed El Bartali, Jean-François Witz, Philippe Dufrenoy, François Demilly, and Eric Charkaluk. Numerical investigation of fatigue strength of grain size gradient materials under heterogeneous stress states in a notched specimen. International Journal of Fatigue, 87:132 - 142, 2016.

[46] Mines Paris Tech and Onera the French Aerospace Lab. Z-set - Non-linear material \& structure analysis suite. http: //www.zset-software.com/, 2019.

[47] J.C. Simo and T.J.R. Hughes. Computational Inelasticity. 1998.

[48] Scipy.org. Minimization using Nelder-Mead simplex method. https://docs.scipy.org/doc/scipy/reference/optimize. minimize-neldermead.html\#optimize-minimize-neldermead, 2019.

[49] Julie Maisonneuve. Fabrication directe de pièces aéronautiques en TA6V et IN718 : Projection et fusion sélective par laser. PhD thesis, Ecole nationale supérieure des Mines de Paris, 2008.

[50] Shang Sui, Jing Chen, Enxiang Fan, Haiou Yang, Xin Lin, and Weidong Huang. The influence of laves phases on the high-cycle fatigue behavior of laser additive manufactured Inconel 718. Materials Science and Engineering: A, 695:6 13, 2017.

[51] Chamara Kumara, Andreas Segerstark, Fabian Hanning, Nikhil Dixit, Shrikant Joshi, Johan Moverare, and Per Nylén. Microstructure modelling of laser metal powder directed energy deposition of alloy 718. Additive Manufacturing, 25:357 $-364,2019$.

[52] Alexandre El Sabbagh. In situ SEM caracterization of the grain boundary sliding mechanism in aluminum at high temperature by field measurement. PhD thesis, Ecole polytechnique, 2018. 